\title{
Joan Pérez de Lazarraga, autor de Dianea \& Koplak (Madrid, 1567), primer novelista y poeta vasco
}

\author{
PATRICIO URQUizU
}

(UNED)

El hallazgo en una biblioteca madrileña de un manuscrito vasco del siglo XVI por parte del historiador Borja Aginagalde, Director del Centro de Documentación del Gobierno Vasco ubicado en el palacio Recalde de Bergara, ha sido en palabras del profesor de la UPV Joseba Lakarra, no sólo uno de los descubrimientos más importantes de estos últimos años, sino incluso algo inimaginable. Dicho manuscrito lo compró la Diputación de Gipuzkoa y en su presentación pública del 18 de febrero de 2004, lo colocó en Internet en su propio portal ${ }^{1}$, poniéndolo a disposición de todos los interesados en la literatura vasca.

Tuvo este descubrimiento un amplio eco en la prensa del País Vasco, en las columnas de estudiosos habituales de la lengua y la literatura vasca como Xabier Kintana, Henrike Knör, Martín Anso, Xabier G. Argüello, Jon Kortazar, David Taberna, Alberto Barandiarán y Pruden Gartzia que inmediatamente dieron su opinión sobre dicho manuscrito.

Tras unos meses de dedicación intensa y exclusiva hemos tenido el honor de realizar y presentar este mismo año de 2004 la primera edición de dicho manuscrito gracias a la labor de la editorial Erein. Dicha obra consta de introducción (pp. 1-70), transcripción moderna (pp. 71-255), índices (257-278), aparato de 730 notas, bibliografía (pp. 279-285), ilustraciones y fac-simil de dicho manuscrito que consta de 51 folios. Aquí intentaremos resumir lo expuesto en dicha edición.

Juan Perez de Lazarraga nacido en Larrea (Álava) hacia 1548 y muerto el 11 de abril de 1605, no es un desconocido, ya que era conocido con el sobrenombre de El Poeta. Era oriundo de Oñate y descendiente de Juan López de Lazarraga que fue secretario de los Reyes Católicos.

Señala Ángel Allende Salazar en su Biblioteca del vascófilo [1887:283], que:

Landazuri en sus «Advertencia á la historia de Alava» dice: «Lazarraga dejó un dilatado manuscrito comprobando la mayor parte de su narración con do-

\footnotetext{
1 www.gipuzkoakultura.net/lazarraga. MS Reserva 091 PERber. Koldo Mitxelena kulturunea.
} 
cumentos literales estampados á su continuación. No se extendió á otra parte alguna de las que integran la historia de Alava, que a escribir de su gobierno político, sin hacer expresión de la antigua y moderna geografía, historia civil y eclesiástica, varones ilustres y todo lo demás de que se necesita para dar una completa historia de cualquier provincia». Elogia al autor por su sólido juicio y laboriosidad; sin embargo, le nota algún defecto y mucha omisión de noticias importantes, y el uso á veces, sin conocerlo, de algún documento supuesto. Floranes, en su «Carta al P. Risco sobre San Prudencio, obispo de Tarazona» habla de Juan Pérez de Lazarraga, señor del palacio de Larrea que escribía por los años 1593, y que presume el Sr. Muñoz y Romero sea el mismo. Floranes no cita esta historia, pero sí un manuscrito muy extenso, en que se trata de su genealogía, y por incidencia de la provincia de Alava.

De dicha genealogía existen varias copias. Una de ellas es un manuscrito de la Biblioteca Nacional de Madrid (MS 11263/7) de la que hemos podido extractar algunos datos sobre la vida de Lazarraga. También hemos consultado el Archivo Diocesano de Vitoria para completar un breve esbozo biográfico.

Resumiendo dichas noticias más las que se deducen de la lectura atenta de los poemas del manuscrito euskérico sabemos que Juan Pérez de Lazarraga nació hacia 1548, que su padre Pedro Perez de Lazarraga estuvo casado con Graciana de Naharria primero y Elena López de Erdoñana después, y que murió en 1564. Que él se halla en Madrid en mayo del 1567, que ya se había casado para el año 1577 con Catalina Gonzalez de Langarica que tuvo una hija casada con Juan Velasco, y que murió el 11 de abril de 1605.

El manuscrito, que dada su paginación de 1138-1204, tal vez formara parte de la gran Historia de Alava, escrita por Lazarraga y que no conocemos, consta de dos partes. Una primera parte escrita en prosa en la que falta el comienzo, el final y tiene destrozos considerables, nos presenta una imitación de la Diana de Jorge de Montemayor. Y su segunda parte se halla formada por una colección de XLVI poemas, de los que nueve se hallan escritos en castellano y el resto en euskera.

Como es sabido Jorge de Montemayor (1520-1561) fue un escritor portugués al servicio de la hija de Carlos V, María de Austria, que publicó diversas obras entre ellas: Cancionero (1554), Segundo Cancionero y Segundo cancionero espiritual (1558) y Los Siete Libros de Diana (1559).

Esta última obra fue considerada como modelo de las novelas pastoriles de la época, a la que imitaron y tradujeron tanto autores españoles como extranjeros. Entre los imitadores se hallan Alonso Pérez, autor de La Segunda parte de la Diana (1563) y Gaspar Gil Polo con su Diana enamorada (1564). Entre las traducciones como señala Eugenia Fosalba ${ }^{2}$ en su tesis sobre ediciones, traducciones e influencias, las hubo al latín, al francés, al italiano, al inglés, al alemán y al catalán.

2 Eugenia FoSAlba: La Diana en Europa. Ediciones, traducciones e influencias. Universidad Autonoma, Barcelona, 1994. 
$\mathrm{Al}$ analizar Maxime Chevalier ${ }^{3}$ el éxito de las Dianas considera que entre otras razones se halla la avidez de lectura de las damas de la época, y que en ella tuvieron que ver tanto la importancia de las mujeres en las disputas de amor de dichas novelas, así como el bucolismo. Éste estaba de moda en la corte castellana, y se hacía eco contradictoriamente del dicho, menosprecio de corte y alabanza de aldea. Así la reina Isabel de Valois, la princesa Juana y las damas de la corte en las mascaradas que tuvieron lugar en 1564, se disfrazaban de pastores, magos, ninfas y sátiros siguiendo a la diosa Diana, cual si la realidad buscara imitar a la literatura ${ }^{4}$.

En la Dianea de Lazarraga ha habido una clara imitación de la de Montemayor pero con unos arreglos. Se han cambiado por ejemplo los nombres de los personajes que participan en la novela del siguiente modo:

$\begin{array}{ll}\text { Montemayor, La Diana (1559) } & \text { Lazarraga, Dianea (1567) } \\ \text { Sireno } & \text { Sirena } \\ \text { Silvano } & \text { Silverio } \\ \text { Selvagia } & \text { Silvia } \\ \text { Dorida } & \text { Dorido } \\ \text { Arsileo (Persona) } & \text { Arsileo (Ciudad) } \\ \text { Felicia (sabia) } & \text { Narvaez (sabio) } \\ \text { Marte } & \text { Marte } \\ \text { Cupido } & \text { Cupido } \\ \text { Salvajes } & \text { Salvajes } \\ - & \text { Clarián }\end{array}$

Narvaez es un personaje que aparece en la novelita El moro Abindarraez y la bella Xarifa que se editó junto a La Diana en Valladolid en 1562, y Clarián es otro personaje pero de la novela de caballerías de Gabriel Velázquez titulada Clarián de Landanis (Toledo, 1518), donde como en la Diana aparece el espejo mágico.

El tema central se puede resumir en un estribillo de un villancico que se hallaba muy de moda en la época:

Amor loco, ; ay, amor loco!

Yo por vos y vos por otro. ${ }^{5}$

${ }^{3}$ Maxime ChEvalier: «La Diana» de Montemayor y su público en la España del siglo XVI». Creación y público en la literatura española. Ed. J.F. Bourel et alt. Castalia, Madrid, 1974, pp. 40-56.

${ }^{4}$ T. FERRER: Nobleza y espectáculo teatral (1535-1622). Estudio y docmentos. Valencia, UNED, 1993.

5 Juan Montero (ed.): Jorge de Montemayor, La Diana. Estudio preliminar de Juan Bautista de Avalle-Arce. Crítica, Barcelona, 1996, p. 58. 
Las cuitas que conforman el círculo amoroso son las siguientes: Silverio se halla enamorado de Sirena que a su vez lo está de Doristeo (a veces llamado Dorido) y éste de Silvia, que se halla enamorada locamente de Silverio. Podemos representar la historia en el siguiente círculo:

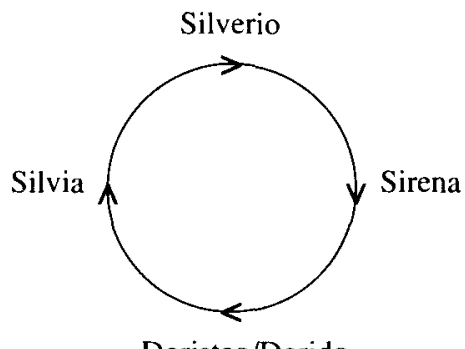

Doristeo/Dorido

Como señala Marcelino Menéndez Pelayo en sus Orígenes de la novela (1905), la Diana de Montemayor es la mejor escrita de todas las novelas pastoriles, por su estilo culto y sin afectación. Aunque la prosa vasca al parecer no se hallaba muy trabajada literariamente, - si exceptuamos la traducción del Nuevo Testamento por Joanes Leizarraga (La Rochelle 1571)-, y el imitador no era sino un joven de unos dieciocho años, no deja de ser interesante esta novela escrita en euskera, la primera novela vasca, redactada en el dialecto nororiental de Álava, que coincide en sus rasgos lingüísticos fundamentales con la variante occidental, es decir, con el vizcaino, y que presenta unas pequeñas variantes respecto a otros dos textos vascos alaveses del siglo XVI, conocidos: el Dictionarium Linguae Cantabricae de Landuccio (1562) y la Doctrina Christiana de Betolaza (1596).

El manuscrito de Lazarraga tenía vocación de libro, aunque por desgracia tuvo que esperar más de cuatro siglos para ser impreso, ya que dice en el folio 46v:

Porque este librico ha de andar por el mundo a donde aunque haya muchas personas que entiendan mejor que yo lo sabre decirlo. En el contenido habrá hartas que ternan deseo de lo saber, me paresció no ser cosa superflua al cabo desta hobrecilla dalle entender a los tales subjetandome en todo a los deseos y discretos para que suplan y corrijan mi ignorancia. Quiero decir, que van en algunas coplas algunas autoridades y nombres castellanos ansí métricos como prosaicos, las cuales aunque como arriba digo hay muchos que las entenderían, habrá también hartos que no estarán en cuenta de lo que por ellas o en ellas quiero decir, por no haber leído la historia y origen dellas y en lo que toca a lo significado dellas. Digo.

Es clara, pues, la confesión de las fuentes castellanas del autor y de sus deseos frustrados de que el librico andara por el mundo. 
El resumen de los poemas por temas y lenguas es el siguiente:

\begin{tabular}{|l|c|c|c|}
\hline \multicolumn{1}{|c|}{ POEMAS } & EUSKARA & CASTELLANO & TOTAL \\
\hline Amorosos & 24 & 2 & 26 \\
Burlescos & 6 & 2 & 8 \\
De refranes & 1 & - & 1 \\
Crónica histórica & 2 & - & 2 \\
Religiosos & 4 & 5 & 9 \\
TOTAL & 37 & 9 & 46 \\
\hline
\end{tabular}

Un total de aproximadamente 2.860 versos, entre los que sobresalen los amorosos. Precisamente el primer poema del Cancionero de Lazarraga , - podríamos denominarlos así-, está compuesto en honor del Amor "Amoriozko errege jaunaren omenez". En él se ve cómo los nobles de Guevara, Ozaeta, Eredia, Ezkerekotxa, etc., se hallan reunidos con sus damas para celebrar las justas del amor, lo que sería habitual en la pequeña corte de los Guevara.

También tiene versos muy habituales en los pliegos sueltos de la época como los de la Bella malmaridada. Son mencionados también Macías $O$ namorado famoso gallego, servidor de Enrique de Villena, prototipo de martir del amor.

Existe un poema que es una protesta de una jovencita contra su padre porque no la quiere casar y se halla escrito en la línea de la canción compuesta por el músico de la corte de Carlos V, Cornelius Canis (Gante, 1506-1562) en francés, cuyo primer verso es Mariez moy, mon père.

Y así como hay algún poema sobre la Bella malmaridada no falta tampoco el de la Bella malmonjada, tema también tópico en la época.

Es curioso reseñar que no todos los poemas que aparecen en el Cancionero se hallan inéditos, pues nos encontramos con un poema en castellano [XLIII], que es la transcripción del pliego suelto titulado, Glosa sobre el romance De la mia gran pena forte...

Una pregunta razonable sería, si ese pliego suelto fue obra de Lazarraga, aunque si se tiene en cuenta que ese pliego se halla junto a Las Coplas de los Comendadores por mi mal os ví, editados en el Cancionero llamado Flor de Enamorados (Barcelona 1562), y que en ese año tendría unos catorce nuestro poeta parece un poco dificil fuera su autor. Aunque también es posible que dicho pliego no fuera de ese año, por lo que la interrogante quedaría en pie.

Es interesante también la Canción-Crónica sobre la Quema de Salvatierra (1564), compuesta en la navidad de ese mismo año, y al parecer para cantar sobre la melodía conocida de Antes era el díalya salía el lucero, que se halla en el Cancionero de La Colombina. ${ }^{6}$

- Al alba venid. Música profana del renacimiento español. Marta Almajano. Ensemble La Romanesca. Dr: José Miguel Moreno. Glossa Music, Fundación Caja de Madrid, 1996. 
Entre los poemas religiosos es de destacar que nos hallamos en el manuscrito con el primer villancico vasco, que es imitación de otro que fue recogido por Francisco de Ocaña en su Cancionero ${ }^{7}$. Y su melodía sería la que recoge Francisco de Salinas en su famosa obra De Musica libri septem (Salamanca 1577), que se refiere Al tono de No me le digays madre a Fray Anton/Buenas nuevas Buenas/Perucho y Antón. Dicha melodía se puede escuchar en el portal de internet señalado abajo. ${ }^{8}$

También hallamos entre los poemas religiosos uno sobre el último juicio, otro sobre María Magdalena, etc.

Resumiendo mucho concluiríamos que Joan Perez de Lazarraga bebe fundamentalmente de tres fuentes. Una es la Biblia y la literatura religiosa de la época. Otra los cancioneros de los siglos XV y XVI, que a su vez recogen los modelos italianos y éstos los grecolatinos. Y en tercer lugar la veta popular, que pone en contacto al poeta con la naturaleza, su terruño y sus costumbres tradicionales.

Es de resaltar también que en dicho Cancionero nos encontramos con tres poemas escritos con otro tipo de letra y lengua (XXXIII, XXXIV, XXXV), que fueron escritos por una mujer, María Estibaliz de Sasiola, perteneciendo este apellido a una familia noble originaria de Deba y Zumaya (Gipuzkoa).

Estos tres poemas se pueden considerar amorosos aunque tienen más de laudatorios, y podemos hallar en ellos fórmulas de canciones populares, como: Mendi altuan erurra dago/Aran baxuan eguzki... [Hay nieve en lo alto y luce el sol en el valle...], y Etai lelo ybai lelo... que aparece también en Detxepare, y es un remedo del Helo, Helo castellano.

Estos poetas del Renacimiento vasco a ambos lados del Pirineo, el navarro Bernat Detxepare, el alavés Joan Perez de Lazarraga, y la guipuzcoana Estibaliz Sasiola, aun siendo cultos por su formación, - no hay que olvidar el fresco del palacio de los gizones de los Lazarraga en Zalduendo (Álava) donde se ve a una mujer leyendo-, está claro que son poetas del pueblo, ya que se expresan en su lengua natal, la de la mayoría de su época: el euskera.

7 Francisco DE OCAÑA: Cancionero para cantar la noche de Navidad y las fiestas de Pascua. Juan de Gracián, Alcala 1603, pp. 18-21.

${ }^{8}$ http://www.cnice.mecd.eos/MaterialesEducativos/mem2001/musical. 